\title{
The Relationship between Violent Video Games Exposure and School Behavior Problems in Qatari Schools
}

\author{
Youssef Hasan* \\ Social Sciences Department, Qatar University, Doha, Qatar \\ *Corresponding author: youssef.hasan@qu.edu.qa
}

\begin{abstract}
Research on violence in movies, television programs, music and video games indicates consistently that media violence increases the aggression and violence, in both immediate/short term and long term contexts. The relationship between violent video games and aggressive behavior is widely studied, but less is known regarding the relationship with school behavior problems. This study investigates the relationship between violent video games exposure and school behavior problems in a sample of 202 students. Multiple regression analysis showed that time spent playing violent video games was positively related to physical fights and antisocial behaviors. This is consistent with a meta-analytic review that found similar violent video game effects for people whether they lived in Western or Eastern countries.
\end{abstract}

Keywords: violent video game exposure, school behavior problem, physical fights, antisocial behavior

Cite This Article: Youssef Hasan, "The Relationship between Violent Video Games Exposure and School Behavior Problems in Qatari Schools." American Journal of Applied Psychology, vol. 5, no. 2 (2017): 63-67. doi: 10.12691/ajap-5-2-5.

\section{Introduction}

Science the late 1970, video game play has been one of the preferred leisure activities for youth. A study surveyed 30,000 online gamers ( $85 \%$ were male) from 2000 to 2003 and found that they spend an average of $22 \mathrm{~h} /$ week playing their chosen video game and $9 \%$ reported spending more than $40 \mathrm{~h} /$ week [1]. The interest in the effects of violent video games started in the early 1990 with the releases of the first-person shooter game, "Wolfenstein 3D" (1992), Mortal Kombat (1992) and Street Fighter (1987) [2]. Over time, the video games are becoming more and more violent. Previously, violent video games featured cartoonish characters but today, these video games have become more graphically realistic and involve more directed forms of violence against realistic human characters.

A number of theories about how and why violent video games affect aggression have been posited, but the most comprehensive theory of the association between the exposure to violent video games and aggression is the general aggression model which was adapted from past theories of aggression [3]. (Figure 1).

According to this model, two types of input variables can influence aggression and antisocial behavior: personal and situational. Personal variables include anything the individual brings to the situation, such as age, gender, genetic predispositions, personality traits and attitudes. Situational variables include all external factors that can influence aggression, such as aggressive cues, drugs and violent video games. The general aggression model suggests that the link between exposure to a situational variable (e.g., violent video games) and the output (e.g., aggressive behavior) is mediated by the present internal state of the individual affects, cognitions and arousal [4]. These internal states are all interconnected. For example, someone who feels angry might also have elevated blood pressure. The types of decisions and appraisals people can make will no doubt influence whether they behave in a nonaggressive or aggressive manner. The final outcomes then cycle through the "social encounter" to become part of the inputs for the next episode. For example, aggressive behavior can influence relationships with family members and friends.

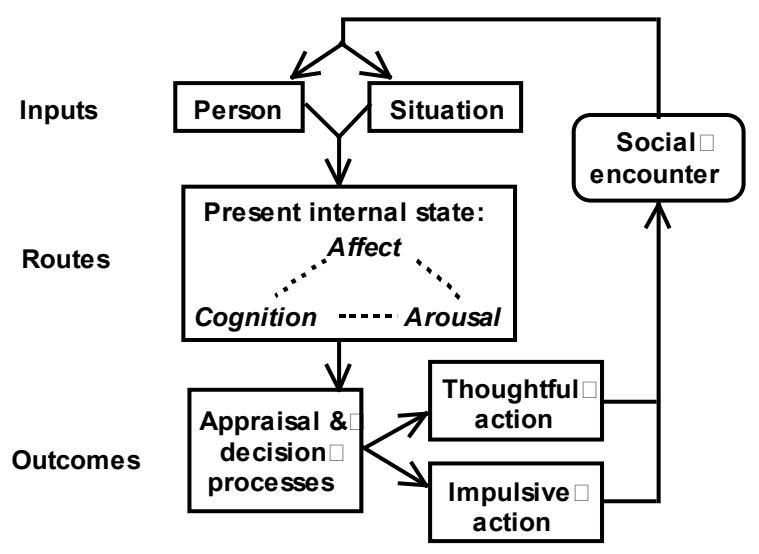

Figure 1. The General Aggression Model 
The present research is the first conducted in Qatar on the link between violent video games exposure and school behavior problems using a sample of Arabic adolescents which increases the generalizability of violent video game effects.

\section{Violent Video Game Effects on Physical Fights and Antisocial Behavior}

Evidence from correlational, longitudinal and experimental research combined a total of 136 research papers with 381 effect size estimates involving over 130,000 participants was reviewed in a meta-analysis conclude that violent video games can increase aggressive behavior, aggressive cognition, aggressive affect, physiological arousal, desensitization to violence, lack of empathy and lower levels of prosocial behavior. The effects occurred for males and females of all ages, regardless of where they lived in the world [5].

Many researchers have presented different interpretations of antisocial behavior. This behavior covers various forms of aggressive and violent behavior, vandalism, failure to follow laws, and harming others [6].

Studies on the relationship between media violence and antisocial behavior have found that exposure to this media makes people prevent another person from winning a prize [7], trying to exploit others [8], and less willing to help victims in need [9].

In an experimental study, participants who played violent video game with a realistic looking gun controller experienced more immersion. This immersion in turn facilitated enjoyment, which led to more aggression [10]

A Three-year longitudinal study found that the aggression-enhancing effect of violent video game play was mediated by aggressive cognitions [11].

Indeed, a longitudinal study showed that the exposure to media violence is the strongest risk factor for violence of students and violent delinquency. This study showed that the more frequently children ages 6 to 10 view violent movies and the more frequently they play violent video games at the beginning of adolescence, the higher these students' violence and delinquency will be at 14 [12].

Also, a longitudinal study reported analyses that combine data from Japanese and USA's samples showed that after taking into account gender and baseline aggressiveness, video gameplay had very similar effects of increasing subsequent aggressiveness across cultures [13].

Another study of a sample of over $6008^{\text {th }}$ - and $9^{\text {th }}$ grade, students who played more violent video games were more likely to see the world as a hostile place, to get into frequent arguments with teachers, and to be involved in physical fights [14]. Reference [15] also showed that those who regularly played violent video games were much more likely to get into physical fights, to hit or beat up someone, to damage property for fun, to report poor school grades and to get into trouble with teachers.

Researchers have also examined associations between exposure to violent video games and delinquent behavior in a sample of at-risk youths. This study showed that frequency of violent video game play was significantly associated with general and violent delinquency [16].

\section{Video Games and Age}

Studies suggested that children and adults are affected differently by exposure to media violence [17]. It is expected that the short-term effects of this media on aggression to be larger for adults than for children and the long-term effects of violent media on aggression to be larger for children than for adults. But there is little evidence of larger effect sizes for younger than for older people [5].

Concerning the aggressive behavior, studies showed that there is evidence for change and stability in aggressive behavior in the course of childhood and adolescent development. A longitudinal study has shown that, from ages 5 to 11 , the number of boys who engage in high levels of physical aggression is stable over time [18].

The aim of the current study is to investigate the relationship between violent video games exposure and school behavior problems. It was expected that participants who exposed to violent video games would engage more in physical fights and demonstrate high levels of antisocial behavior during the academic year. We also expected a role of age in the relationship between violent video game exposure and school behavior problems.

\section{Method}

\subsection{Participants}

Two hundred and two male students voluntarily participated in the study. Participants ranged in age from 14 to 17 years of age $(M=15.85 ; S D=0.86)$. They were recruited from Doha schools (Qatar).

\subsection{Procedure}

The survey consisted of three sections: Section A contained demographic questions, Section B contained questions regarding the video game habits and Section $\mathrm{C}$ consisted questions about the target adolescent's behavior at school. Letters were mailed directly to the parents of students in participating classrooms informing them about the study and requesting consent. Each participant completed an anonymous survey that gathered descriptive data about students' knowledge about video games, selfreport scale of behavior at school and demographic data. Students were instructed that video games included any games played on computer, video game consoles (such as Nintendo), on hand-held game devices (such as Gameboy), or in video arcades.

\subsection{Measures}

\subsubsection{Violent Video Game Exposure}

Participants were asked to name their two favorite video games. For each game named, participants were asked to rate how frequently they played the game on a 5 point Likert scale (1="rarely", 5="every day"). To establish the extent to which the video games included violent contents, 3 experts were asked to rate each game in 
terms of violent content. Similar to Reference [19], experts were given the following instructions: For each of the following games, please rate the level of violent content. In making your judgment, please consider the following aspects: (a) How realistic are the scenes in which characters are injured and killed (e.g. groaning noises, blood splashing, body parts flying); (b) How realistic is the presentation of opponents (monsters, aliens vs. human-shape characters); (c) How realistic is the presentation of scenes in which one's own character gets injured or killed? Raters classified each game on a five-point scale that ranged from "free of violent content" (1) to "high level of violent content" (5). A video game violence exposure score was computed for each participant by multiplying the frequency of play for each game by its violence, and taking the mean of the two products.

\subsubsection{Weekly Amount of Video Game Play}

Similar to literature of specialty [20], Participants reported the amount of time they spent playing video games during different time periods on weekdays and weekends. Weekly amounts were calculated from these responses.

\subsubsection{Physical Fight}

Participants were asked how often they had been in a physical fight since the beginning of the school year, how often they had hit students to the point they had been injured or bleeding and how often they used beating to resolve all disputes in school. Responses were rated on a 5-point Likert scale (ranging from 1 to 5 times) and an open-ended question if they had more than 5 times. Responses were coded such that higher scores indicate higher physical fight. Coefficient alpha was satisfactory ( $\alpha$ $=.93)$.

\subsubsection{Antisocial Behavior}

Participants were asked how often they had destroyed intentionally school properties since the beginning of the school year, how often they had insult students in front of them or by sending a SMS since the beginning of the school year, how often they had intentionally harassed or annoyed students since the beginning of the school year, and how often they had intentionally harassed or annoyed teachers since the beginning of the school year. Responses were rated on a 5-point Likert scale (ranging from 1 to 5 times) and an open-ended question if they had more than 5 times. Responses were coded such that higher scores indicate higher antisocial behavior. Coefficient alpha was satisfactory $(\alpha=.95)$.

\section{Results}

\subsection{Intercoder Reliability}

The ratings of violent content provided by three independent raters showed a high inter-rater agreement. The intraclass correlation coefficient for the three independent raters was .92 [21]. On the basis of this high level of agreement, violence ratings were averaged across all three raters to provide an index of violent content for each game.

\subsection{General Amount of Video Games Exposure}

The average amount of participants spent playing video games was 7 h49 per week.

\subsection{Correlation between Variables}

As shown in Table 1, exposure to violent video game content was positively correlated with physical fights and antisocial behavior and negatively correlated with age. The amount of video game play was positively correlated with antisocial behavior and negatively correlated with age.

Table 1. Correlation between main study variables

\begin{tabular}{lcccc}
\hline & Amount & Age & $\begin{array}{c}\text { Physical } \\
\text { Fights }\end{array}$ & $\begin{array}{c}\text { Antisocial } \\
\text { Behavior }\end{array}$ \\
\hline VVGE & $.328^{* *}$ & $-.289^{* *}$ & $.228^{* *}$ & $.210^{* *}$ \\
Amount & & $-.157^{*}$ & .103 & $.180 *$ \\
Age & & -.092 & -.078 \\
Physical Fights & & & & $.922 * *$ \\
\hline
\end{tabular}

$* P<0.05 ; * * P<0.01$

VVGE: Violent video game exposure; Amount: Amount of video game play; Physical Fights: Physical fights at school; Antisocial Behavior: Antisocial behavior at school.

\subsection{Primary Analyses}

\subsubsection{Physical Fights}

Given the high intercorrelations among violent video game content, amount of video game play, physical fights, antisocial behavior and age, it would be reasonable to question whether violent video game exposure contributes independently to fights and antisocial behavior. Multiple regression was conducted using physical fights as the dependent variable (see Table 2). Amount of video game play per week and age were entered in Step1. In Step2, we entered violent video game exposure. Violent video game exposure contributed a significant amount of variance when controlling for amount of video game play and age $F(3,198)=3.43, p<0.01$.

Table 2. Regression Analysis Predicting Physical Fights

\begin{tabular}{lccccc}
\hline Predictor & $B$ & $T$ & S.E. & $R^{2}$ & df \\
\hline Step 1: Age & -0.08 & -1.09 & 0.29 & & \\
Amount & 0.01 & 1.27 & 0.21 & 0.02 & \\
Step 2: VVGE & 0.21 & 2.79 & 0.001 & 0.05 & 3,198 \\
\hline
\end{tabular}

Amount: Amount: Amount of video game play; VVGE: Violent video game exposure.

\subsubsection{Antisocial Behavior}

Similar analysis was conducted for the variable antisocial behavior. Multiple regression was conducted using antisocial behavior as the dependent variable (see Table 3). Amount of video game play per week and age were entered in Step1. In Step2, we entered violent video game exposure. Violent video game exposure contributed a significant amount of variance when controlling for amount of video game play and age $F(3,198)=4.06, p<0.01$. 
Table 3. Regression Analysis Predicting Antisocial Behavior

\begin{tabular}{lccccc}
\hline Predictor & $B$ & $T$ & S.E. & $R^{2}$ & df \\
\hline Step 1: Age & -0.06 & -0.73 & 0.47 & & \\
Amount & 0.17 & 2.44 & 0.02 & 0.04 & \\
Step 2: VVGE & 0.17 & 2.20 & 0.03 & 0.06 & 3,198 \\
\hline
\end{tabular}

Amount: Amount: Amount of video game play; VVGE: Violent video game exposure.

\subsubsection{Difference Age}

We tested weather participants' age moderated the exposure of violent video game on physical fights and antisocial behavior. Continuous predictor variables were centered, to reduce multicol-linearity. Results showed that the interaction between violent video game exposure and participants' age on physical fights was nonsignificant, $\beta=.09, t(3,198) 1.31, p=.19$. Also, results showed that the interaction between violent video game exposure and participants' age on antisocial behavior was nonsignificant, $\beta=.09, t(3,198) 1.26, p=.21$.

\section{Discussion}

Meta-analysis provide strong evidence that playing violent video games is a significant causal risk factor for both short and long term increases in aggression [4,5].

The main purpose of the present research was to investigate the relationship between violent video games exposure and school behavior problems. The more students played violent video games rated as violent by independent judges, the more they were likely to have physical fights and antisocial behavior.

It is true that the general amount of video games exposure was significantly correlated with physical fights and antisocial behavior, which also demonstrated by studies [22], several studies demonstrate that exposure to violent media is a better predictor of aggression than exposure to media in general [22,23].

The strengths of this study are that it included the ability to measure more extreme forms of aggression (e.g., physical fights) that cannot be measured in experimental studies. Moreover, this study was the first conducted on a sample of Arab adolescents on the effect of violent video games, which confirmed that these games also related positively to school behavior problems among Arab students. This is consistent with a meta-analytic review that found similar violent video game effects for people of all ages, regardless of whether they lived in the world [5].

Participant's age did not moderate the relationship between violent video game exposure and physical fights and antisocial behavior. It was mentioned in previous studies that younger children are likely to be more affected by the exposure of media violence than adults. But more research is needed to clarify this issue. A television study found that even late adolescents are also affected by the media [22]. Research in age effect is lacking in the violent video games literature [5], and more research is needed to understand the age difference on the violent video game effects.

The interpretation of our findings is however limited by the self-report nature of the study, which mostly relies on the memory of the respondents and is therefore subject to error. However, considerable research suggests that self-report is an applicable way of collecting accurate data and that measures utilized have been shown to be both reliable and effective, and when confidentiality is assured [24].

\section{References}

[1] Yee, N. (2006). The Demographics, Motivations, and Derived Experiences of Users of Massively Multi-User Online Graphical Environments. Presence: Teleoperators and Virtual Environments, 15, 309-329.

[2] Carnagey, N. L., \& Anderson, C. A. (2004). Violent video game exposure and aggression: A literature review. Minerva Psichiatrica, 45, 1-18.

[3] Anderson, C. A., \& Bushman, B. J. (2002). Human aggression. Annual Review of Psychology, 53, 27-51.

[4] Anderson, C. A., \& Bushman, B. J. (2001). Effects of violent video games on aggressive behavior, aggressive cognition, aggressive affect, physiological arousal, and prosocial behavior: A meta-analytic review of the scientific literature. Psychological Science, 12, 353-359.

[5] Anderson, C. A., Shibuya, A., Ihori, N., Swing, E. L., Bushman, B.J., Sakamoto, A., Rothstein, H.R., \& Saleem, M. (2010). Violent video game effects on aggression, empathy, and prosocial behavior in Eastern and Western countries. Psychological Bulletin, 136, 151-173.

[6] Mayer, G. (1995). Preventing antisocial behavior in the schools. Journal of Applied Behavior Analysis, 28, 467-478.

[7] Saleem, M., Anderson, C. A., \& Gentile, D. A. (2012). Effects of prosocial, neutral, and violent video games on children's helpful and hurtful behaviors. Aggressive Behavior, 38, 281- 287.

[8] Sheese, B. E., \& Graziano, W. G. (2005). Deciding to defect: The effects of video-game violence on cooperative behavior. Psychological Science, 16, 354-357.

[9] Bushman, B. J., \& Anderson, C. A. (2002). Violent video games and hostile expectations: A test of the general aggression model. Personality and Social Psychology Bulletin, 28, 1679-1686.

[10] McGloin, R., Farrar, K. M., Krcmar, M., Park, S., \& Fishlock, J. (2016). Modeling outcomes of violent video game play: Applying mental models and model matching to explain the relationship between user differences, game characteristics, enjoyment, and aggressive intentions. Computers in Human Behavior, 62, 442-451.

[11] Gentile, D. A., Bender, P. K., \& Anderson, C. A. (2017). Violent video game effects on salivary cortisol, arousal, and aggressive thoughts in children. Computers in Human Behavior, 70, 39-43.

[12] Hopf, W. H., Huber, G. L., WeiB, R. H. (2008). Media violence and youth violence: a 2-year longitudinal study. Journal of Media Psychology, 20, 79-96.

[13] Anderson, C. A., Sakamoto, A., Gentile, D. A., Ihori, N., \& Shibuya, A., Yukawa, S., Naito, M., Kobayashi, K. (2008). Longitudinal Effects of Violent Video Games Aggression in Japan and the United States. Pediatrics, 122, 1067-1072.

[14] Gentile, D. A., Lynch, P. J., Linder, J. R., Walsh, D. A. (2004). The effects of violent video game habits on adolescent hostility, aggressive behaviors, and school performance. Journal of Adolescence, 27, 5-22.

[15] Kutner, L., \& Olson, C. (2008). Grand theft childhood: The surprising truth about violent video games and what parents can do. New York: Simon \& Schuster.

[16] DeLisi, M., Vaughn, M. G., Gentile, D. A., Anderson, C. A., \& Shook, J. (2013). Violent video games, delinquency, and youth violence: New evidence. Youth Violence and Juvenile Justice, 11, 132-142.

[17] Bushman, B. J., \& Huesmann, L. R. (2006). Short-term and longterm effects of violent media on aggression in children and adults. Archives of Pediatrics \& Adolescent Medicine, 160, 348-352.

[18] Lee, K., Baillargeon, R. H., Vermunt, J. K., Wu, H., \& Tremblay, R. E. (2007). Age differences in the prevalence of physical aggression among 5 - 11 - year - old Canadian boys and girls. Aggressive Behavior, 33, 26 - 37. 
[19] Krahé, B., \& Moeller, I. (2004). Playing violent electronic games, hostile attributional style, and aggression-related norms in German adolescents. Journal of Adolescence, 27, 53-69.

[20] Anderson, C. A., \& Dill, K. E. (2000). Video games and aggressive thoughts, feelings, and behavior in the laboratory and in life. Journal of Personality and Social Psychology, 78, 772-790.

[21] Shrout, P. E., Fleiss, J. L. (1979). Intraclass correlations: Uses in assessing rater reliability. Psychological Bulletin, 86, 420-428.
[22] Johnson, J. G., Cohen, P., Smailes, E. M., Kasen, S., \& Brook, J. S. (2002). Television viewing and aggressive behavior during adolescence and adulthood. Science, 295, 2468-2471.

[23] Anderson, C. A., Gentile, D. A., \& Buckley, K. (2007). Violent video game effects on children and adolescent: Theory, research and public policy. New York: Oxford University Press.

[24] Hagan, F. E. (2003). Research methods in criminal justice and criminology. Boston: Allyn \& Bacon. 